\title{
Environmental co-benefits and trade-offs of climate mitigation strategies applied to net-zero-emission neighbourhoods
}

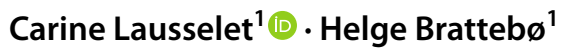

Received: 6 April 2021 / Accepted: 31 August 2021 / Published online: 23 September 2021

(c) The Author(s) 2021

\begin{abstract}
Main purpose To limit global warming at a safe level of $1.5^{\circ} \mathrm{C}$, deep emission reductions in all sectors combined with rapid, far-reaching, and unprecedented changes in all aspects of society are required. The ongoing climate urgency has led to greenhouse gas (GHG) emissions to be the most often inventoried life-cycle indicators. But, to draw comprehensive climate mitigation strategies (CMS), adverse potential environmental side-effects and trade-offs should be assessed as well.

Methods LCA is used to assess the potential environmental co-benefits and trade-offs of a net-zero-emission neighbourhood (nZEN) in the early planning stages. CMS are designed to test for the effect of (1) mobility patterns less based on the use of passenger cars, (2) a better material use by decreasing the size of the dwellings and increasing the passenger loads, (3) increased lifetimes of buildings and passenger cars, and (4) their combination.

Results Across the impact categories, environmental benefits of 5-20\% are shown for single CMS and of 22-42\% when combined. Interestingly, the highest environmental co-benefits are found for Metal Depletion, highlighting the close interconnection of CMS and decreased pressure on resource use.

The use of several climate metrics has shed light on the use of fossil fuels in the production value chains of the materials used to provide the mobility services and shelters to the inhabitants of the nZEN under study. A combination of climate metrics with short- and long-time horizon should be used to give the importance that short-lived GHG such as methane deserve in the climate debate.

Conclusion To best mitigate climate change along with environmental co-benefits on a nZEN level, measures should be taken at different points in time. At the early planning stages, incentives should be in place that promote dwellings of reasonable sizes (measured per inhabitant) along with incentives to decarbonize the materials value chains, in- and out-land. Over time, a culture of car- and ride-sharing will have positive environmental benefits. When renovating, incentives that promote the reshaping of dwellings into dwellings of smaller sizes will help to shift the sole focus on nZEB standards to multi-layers strategies.
\end{abstract}

Keywords Net-zero-emission neighbourhood $\cdot$ Multi-layer climate mitigation strategy $\cdot$ Car- and ride-sharing $\cdot$ Smaller dwelling size

\section{Introduction}

Global warming induced by human activities is increasing at an unprecedent rate (IPCC 2018). In 2019, the total global final energy use of the building sector remained at the same level compared to previous years. But $\mathrm{CO}_{2}$ emissions stemming from the final energy use (operational phase) of

Lausselet C.

carine.lausselet@ntnu.no

1 Norwegian University of Science and Technology, NTNU, Trondheim, Norway buildings were at the highest level ever recorded with a share of $28 \%$ of the total global energy-related $\mathrm{CO}_{2}$ emissions. The continued use of coal, oil, and natural gas for heating and cooking in combination with high-activity levels in regions with carbon-intensive electricity were responsible for the increase. In addition, $10 \%$ of the total global energy-related $\mathrm{CO}_{2}$ emissions can be reallocated from the overall industry sector to the industries devoted to manufacturing construction materials such as steel, cement, and glass (IEA 2020a).

To limit global warming at a safe level of $1.5^{\circ} \mathrm{C}$, deep emission reductions in all sectors combined with rapid, farreaching, and unprecedented changes in all aspects of society 
are required (IPCC 2018). Time is running, and we need to move fast. Multi-layers climate mitigation strategies (CMS) will be most effective. For the building sector, the energy demand should be reduced while the energy sector should be decarbonized and strategies that reduce life-cycle material $\mathrm{CO}_{2}$ emissions should be implemented (UNEP 2020).

Energy losses can be minimized by both renovating the existing building stock and constructing new buildings according to low-energy-use standards such as nearly-zeroenergy building. According to the Energy Performance of Building Directive (European Commission 2010), a nearly zero-energy building is a "building that has very high energy performance and where the nearly zero- or very low-energy need is covered to a very significant extent by energy from renewable sources, including energy from renewable sources produced on-site or nearby." In Norway, the nearly-zero-energy building concept is translated in greenhouse gas (GHG) emission terms and becomes a net-zero-emission-building (nZEB) balance (Fufa et al. 2016). By undertaking a consequential approach, the GHG emissions occurring during the different life-cycle stages of a nZEB are compensated by sending the surplus renewable energy produced locally to the grid. Several nZEBs become a net-zero-emission neighbourhood (nZEN) (Wiik et al. 2018). By using the surplus energy locally produced in a nZEN to substitute power generated from fossil fuels or to replace fossil fuels used in mobility, nZEN projects will contribute to a low-carbon society.

The life-cycle material GHG emissions can be reduced by a better material efficiency that results in the same material services provided but with less material production and processing (Allwood et al. 2011). Material efficiency can be measured by quantifying material use by the total weight of materials or in service units to respond to human needs such as housing or recreation (Zhang et al. 2018). According to Hertwich et al. (2019), material efficiency such as (a) a more intensive use, (b) lifetime extension, (c) light-weighting, (d) reuse of components, (e) recycling, upcycling, and cascading, and (f) improving yield in production, fabrication, and waste processing will help to provide shelter and automotive transport with less materials and lower overall GHG emissions.

Demand-side material efficiency strategies are complementary to those obtained through the decarbonization of our energy system and may offer substantial GHG mitigation potentials (UNEP 2019). For the built environment, a combination of material efficiency strategies at different points in time will best mitigate climate change (Lausselet et al. 2020b). In the early planning stages, thresholds on floor area per inhabitant can be encouraged and materials with low environmental impact should be preferred. Over time, a good maintenance of the buildings will postpone the renovation needs and extend the buildings' lifetime. For passenger vehicles, material efficiency measures such as more intensive use by means of increased vehicle occupancy and vehicle downsizing by switching to smaller vehicles will allow for quick emission reductions (Wolfram et al. 2020). But the importance of material use and related embodied emissions is still overshadowed by policies focusing on energy efficiency and the deployment of low-carbon energy supply. Climate-change mitigation policy would benefit from a greater integration of material efficiency strategies that could significantly increase the emission coverage of existing product policies (Scott et al. 2018).

Life-cycle assessment (LCA) allows us to estimate how potential environmental impacts accumulate over the different life-cycle phases and elements of a system. LCA results provide a basis for identifying environmental bottlenecks and for comparing a set of alternative scenarios with respect to environmental impacts (Finnveden et al. 2009; Hellweg 2014). LCA is the preferred method for quantifying direct and embodied building-related GHG emissions (Zhao et al. 2019). LCA is increasingly used to evaluate the environmental performance of more complex systems such as neighborhoods that encompass several sub-systems such as the built-environment system, the mobility-fleet system, and the energy system (Lausselet et al. 2019, 2020a, 2021; Stephan and Crawford 2014; Stephan and Stephan 2016). Those studies all show (1) the shared environmental impact of the built environment and the mobility parc and (2) the importance of the embodied emissions in materials, especially when high energy-performance standards are in place. Buildings should not be analyzed as individual elements but should be contextualized to fully capture the broader impacts linked to their inhabitants and their location such as mobility patterns.

The ongoing climate urgency has led to $\mathrm{CO}_{2}$ and other GHG emissions to be the most often inventoried life-cycle indicators. But, in order to draw comprehensive CMS, adverse potential environmental side-effects and trade-offs should be assessed as well. By including the time dimension, the aspiration is to identify strategic choices needed at different points in time to make the necessary provisions allowing for the nZENs to deploy their full potential.

Consequently, and in view of the stringent short- and long-term climate objectives and the need to implement them locally, the main value of this work is to conduct a comprehensive LCA on a nZEN in the early planning stages with a time dimension to (1) assess the environmental potential co-benefits and trade-offs of a nZEN in the early planning stages, (2) develop CMS highlighting key strategic considerations and limitations around the identified technical potential, (3) compare the identified environmental reduction potential and trade-offs with what has been realized in the current project, and (4) provide recommendations on when the different CMS must be in place. 
This paper is organized as follows: Sect. 2 describes the methodology and the case study, Sect. 3 describes the main results of the analysis, Sect. 4 continues with a discussion on the results, including uncertainties, barriers, opportunities, and policy implications now and towards 2050, and Sect. 5 provides concluding remarks.

\section{Methods}

In this section, the different parts of the model (buildings, infrastructure, mobility, energy supply, and emission credits) and their evolution over time are described first. Then, the case study is presented, followed by a description of the Baseline scenario and the four CMS.

\subsection{Model description}

The model used in this study is based on the model developed by Lausselet et al. (2020a) and Lausselet et al. (2019). The model is further developed to (1) compute detailed annual energy balances, (2) include mobility-related infrastructure, and (3) include several impact categories.

If nothing else is specified, Ecoinvent (version 3.2, allocation cut-off, Wernet et al. (2016)) is used for background data. ReciPe v1.12 (with a hierarchist perspective) is chosen for the impact method (Goedkoop et al. 2013). Arda, a Matlab-routine-based program developed at NTNU (Majeau-Bettez and Strømman 2016), is used for the LCA calculations and further structural path analyses to analyze the results.

Inside each impact category $i$, the total environmental impacts of the neighbourhood $E I_{t o t, i}$ over the period of assessment (POA) are described in Eq. (1) and are equal to the sum of the environmental impacts caused by the construction of the buildings $E I_{B(M c),}$, the replacement of building materials $E I_{B(M r), i}$, the production of the transportation modes $E I_{M o b(M c), i}$ used to fulfill the mobility needs of the inhabitants, the operational phase of those transportation modes $E I_{M o b(O), i}$, the related mobility infrastructure $E I_{\operatorname{Inf}-M o b(M c), i}$, the construction and replacement of the infrastructure in the

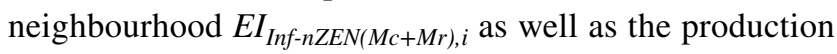
and operation of the on-site energy $E I_{E n(M c+M r, O) i}$. Subtracted from this sum is the environmental credits $E I_{E l(\text { surplus }), i}$ gained by sending the surplus electricity produced locally to the grid that replaces an average European electricity mix based on fossil fuels.

$$
\begin{aligned}
E I_{t o t, i}= & E I_{B(M c), i}+E I_{B(M r), i}+E I_{M o b(M c), i}+E I_{M o b(O), i} \\
& +E I_{I n f-M o b(M c), i}+E I_{I n f-Z E N(M c+M r), i} \\
& +E I_{E n(M c+M r, O), i}-E I_{E l(\text { surplus }), i}
\end{aligned}
$$

Referring to the European Committee for Standardization (2012), Mc refers to the product stage or embodied emissions stemming from material production (modules A1-A3), $M r$ refers to the material replacement (B4) in the use stage, and $O$ refers to the operational energy use in buildings (B6) and mobility (B8), according to the new Norwegian standard NS 3720 "Method for greenhouse-gas calculations for building" (NS 2018) that accounts for transportation in a separate module.

Each elements of Eq. (1) is further developed in the following sub-sections. Common to all the sections is the use of three datapoints in 2021, 2030, and 2050 to dynamically developed certain parameters over time to factor in a better efficiency of the production processes and an increase of the reuse and use of recycled materials. The parameters are developed linearly from 2021-2030 and 2030-2050 and kept constant from 2050 to the end of the POA.

\subsubsection{Buildings}

For each impact category $i$, the total environmental impact embodied in building materials $E I_{B(M c), i}$ is calculated according to Eq. (2). For each building type $t, B_{t}$ is the number of building types $t, m_{m t}$ is the quantity of material $m$ of type $m t$ per building type $t$, and $I i_{m t, 2021, i}$ is the impact intensity of material $m t$ for a given impact category $i$ at the year of construction.

$E I_{B(M c), i}=\sum_{t} \sum_{m t} B_{t} \cdot m_{m t, t} \bullet I i_{m t, 2021, i}$

The total environmental impact embodied in building materials because of the replacement of building materials $E I_{B(M r), i}$ over the POA is calculated according to Eq. (3) with the help of the service life $S L_{m t}$ of each material type $m t$. An overall decrease of $30 \%$ is due to an assumed better efficiency of the production processes of the main materials based on the figures provided by ESU and IFEU (2008) in addition to an increase of the reuse and use of recycled materials over time. Thus, for $y>2021, I i_{m t, y, i}=0.7 \cdot I i_{m t, 2021, i}$. The future values of $I i_{m t, y, i}$ are not decreased linearly from 2021 because the first renovation will not occur before 30 years.

$$
E I_{B(M r), i}=\sum_{y=2021}^{y=2080} \sum_{t} B_{t} \cdot m_{m t, t} \bullet I i_{m t, y, i} \bullet\left(\frac{P O A}{S L_{m t}}-1\right)
$$

\subsubsection{Mobility}

For each impact category $i$, the total environmental impact embodied in the production of the transport modes $E I_{M o b(M c), i}$ over the POA is determined by Eq. (4). $\alpha_{t m, y}$ 
stands for the share of the different transport modes $\mathrm{tm}$ (foot, bike, passenger car, bus, and train) at year $y . \beta_{t m, v t, y}$ stands for the distribution of each technology $v t$ of transport mode $t m$ at year $y$. The passenger-car parc comprises electric cars and conventional cars powered by gasoline and diesel. The buses and trains include both electric and diesel-powered engines. $I i_{t m, v t, y, i}$ is the impact intensity for the transport mode $t m$ with a technology $v t$ at year $y$ for the impact category $i$. $L_{t o t}$ stands for the total distance travelled yearly by the inhabitants of the neighbourhood.

$E I_{M o b(M c), i}=\sum_{y=2021}^{y=2080} \sum_{t m} \sum_{v t} \alpha_{t m, y} \cdot \beta_{t m, v t, y} \cdot I i_{t m, v t, y, i} \bullet L_{t o t}$

$\alpha_{t m, y}$ is case-specific and is described further in this section. The technology distribution is embedded in the model and is for $t m=$ passenger cars of $\beta_{\text {tm,electric, } 2021}=13 \%$, $\beta_{\text {tm,diesel, } 2021}=51 \%$, and $\beta_{\text {tm, gasoline } 2021}=36 \%$ in 2021 followed by $\beta_{\text {tm,electric, } 2030}=53 \%, \beta_{\text {tm, diesel, } 2030}=30 \%$, and $\beta_{\text {tm, gasoline } 2030}=17 \%$ in 2030 , and $\beta_{\text {tm,electric }, 2050}=95 \%$, $\beta_{\text {tm,diesel, } 2050}=4 \%$, and $\beta_{\text {tm, gasoline }, 2050}=1 \%$ in 2050 . Those figures are based on figures computed by the Norwegian Institute of Transport Economics (Fridstrøm and Østli 2016). The technology shares for trains represent the current situation in Norway and are, for $t m=$ train, $\beta_{\text {tm,electric }, 2021}=80 \%, \beta_{\text {tm, diesel, } 2021}=20 \%$ followed by $\beta_{\text {tm,electric,2030 }}=\beta_{\text {tm,electric }, 2050}=100 \%$ and $\beta_{\text {tm, diesel, } 2030}=$ $\beta_{\text {tm, diesel, } 2050}=0 \%$.

$I i_{t m, v t, 2030, i}$ and $I i_{t m, v t, 2050, i}$ are assumed to be $20 \%$ and $50 \%$ lower than their respective $I i_{t m, v t, 2021, i}$ counterparts, respectively, because of a better efficiency in the production processes of the main materials based on ESU and IFEU (2008) in addition to an increased reuse and use of recycled materials over time.

$E I_{M o b(O), i}$ is calculated according to Eq. (5).

$$
E I_{M o b(O), i}=\sum_{y=2021}^{y=2080} \sum_{t m} \sum_{v t} \alpha_{t m, y} \cdot \beta_{t m, v t, y} \cdot I i_{t m, v t, y, i} \cdot L_{t o t}
$$

For electric vehicles (passenger car, bus, and train), $I i_{t m, v t, y, i}$ is computed by multiplying the electricity use by its impact intensity inside each impact category $i$. The electricity use is of $17.1 \mathrm{kWh} / 100 \mathrm{~km}$ for electric cars (Ellingsen et al. 2016), of $16.4 \mathrm{kWh} /($ person $100 \mathrm{~km}$ ) for electric trains (Ecoinvent Centre 2015), and of $18.3 \mathrm{kWh} /$ (person $100 \mathrm{~km}$ ) for electric buses (based on numbers for Norway). Electric cars are supplied by the electricity produced on-site, whereas electric trains and buses are fed by the national electricity mix. The operational energy of all the transport modes is assumed to decrease over time. $I i_{t m, v t, 2030, i}$ and $I i_{t m, v t, 2050, i}$ are decreased by respectively $10 \%$ and $20 \%$ compared to $I i_{t m, v t, 2021, i}$ on the basis of numbers from Ajanovic (2015) and Cox et al. (2018).

\subsubsection{Mobility-related infrastructure}

For each impact category $i$, the total environmental impact embodied in the production of the mobility-related infrastructure $E I_{I n f-M o b(M c), i}$ is computed with Eq. (6).

$E I_{I n f-M o b(M c), i}=\sum_{y=2021}^{y=2080} \sum_{t m} \alpha_{t m, y} \cdot I i_{t m, i} \cdot L_{t o t}$

$I i_{t m, i}$ is the impact intensities of the infrastructure related to each transport mode $t m$. No future decreases are assumed for $I i_{t m, i}$ because of the long infrastructure lifetime.

\subsubsection{On-site infrastructure}

For each impact category $i$, the total environmental impact embodied in the production of the on-site infrastructure $E I_{I n f-n Z E N(M c+M r), \mathrm{i}}$ is computed with Eq. (7).

$E I_{I n f-n Z E N(M c+M r), i}=\sum_{y=2021}^{y=2080} \sum_{e} \sum_{m t} I e l_{e} \cdot m_{m t, e} \cdot I i_{m t, y, i}\left(1+\frac{P O A}{S L_{m t}}\right)$

For each infrastructure element $e$, each quantity $m$ of material $m t$ is multiplied by its impact intensity $I i_{m t, y, i}$. For $y>2021$, the values of $I i_{m t, y, i}$ are set to $50 \%$ of $I i_{m t, 2021, i}$ based on a better efficiency in the production processes of the main materials based on ESU and IFEU (2008) in addition to an increased reuse and use of recycled materials over time.

\subsubsection{On-site energy production}

The production and operation of the on-site energy $E I_{E n(M c+M r, O), i}$ is computed with Eq. (8).

$E I_{e n(M c+M r, O), i}=\sum_{y=2021}^{y=2080} \sum_{p t} E n_{p t, y} \cdot I i_{p t, y, i}$

$E n_{p t, y}$ denotes the energy produced by the production technology $p t$ at year $y$ and $I i_{p t, y, i}$ is the emission intensity of the energy production technology $p t$ in year $y$. For photovoltaic solar panels (PV), $I i_{P V, 2050, i}=0.5 \cdot I i_{P V, 2021, i}$ based on Gibon et al. (2017a) and for combined heat and power (CHP), $I i_{C H P, 2050, i}=0.9 \cdot I i_{C H P, 2021, i} \cdot I i_{C H P, 2050, i}$ is decreased by $10 \%$ only because this technology is already at an advanced deployment stage and little future improvements in the process efficiency can thus be expected.

\subsubsection{Environmental credits}

The potential environmental credits $E I_{E l(\text { surplus }), i}$ are based on the annual electricity balance as depicted in Eq. (9). 
$E I_{E l(s u r p l u s), i}=\sum_{y=2021}^{y=2080} \sum_{p t}\left(E l_{\text {On-site,pt,y }}-\left(E l_{\text {use }, B, y}+E l_{\text {use,el } l_{\text {car }, y}}+E l_{\text {use,on-siteinf,y }, y}\right)\right) \cdot \gamma_{p t, y} \cdot I i_{p t, y}$

At year $y, E I_{E l(\text { surplus }), i}$ is the result of the electricity produced locally $E l_{\text {on-site,pt,y }}$ by each production technology $p t$ minus the electricity used to cover the electricity needs of the buildings $E l_{\text {use,t,y }}$, the electricity to supply the passenger cars $E l_{\text {use,el_car, } y}$, and the electricity used for the lighting of the neighbourhood $E l_{\text {use,on-site inf } y \text {. This first convolution is }}$ multiplied by the environmental intensity of the European electricity mix computed by multiplying the share of the different energy technologies $p t$ at year $y \gamma_{p t, y}$ with their respective environmental impact intensity $I i_{p t, y}$ at time $y \cdot \gamma_{p t, y}$ is taken from the last electricity-generation figures by source in the European Union in the Sustainable Development Scenario ( $<1.5^{\circ} \mathrm{C}$ target), 2019-2050 (IEA 2020b). $I i_{p t, y}$ are taken from life-cycle inventory data for electricity generation developed and used by Gibon et al. (2017b), Arvesen et al. (2018), and Pehl et al. (2017).

\subsection{Case study}

The LCA model described above is applied on Ydalir, a neighbourhood in the early planning stages located in Elverum, Norway. Ydalir consists of one school $\left(6474 \mathrm{~m}^{2}\right)$, one kindergarten $\left(2140 \mathrm{~m}^{2}\right)$, and 1000 residential buildings (of $100 \mathrm{~m}^{2}$ each). The school and the kindergarten were taken into use in autumn 2019, and the residential buildings will be built over the next 15-20 years. Yet, to simplify the assessment, we assumed all the construction to occur at the beginning of the assessment period in 2021. The POA of the study is equal to the building lifetime of 60 years (Wiik et al. 2018). The life-cycle inventories of all the sub-systems are given in the supplementary material.

The functional unit is "to fulfil the housing, school, kindergarten, and mobility needs of the 2500 inhabitants of Ydalir over a 60-year time period."

Ydalir has high climate-change-mitigation ambitions clearly stated in its master plan (Ydalir 2017). Ydalir will "produce its energy locally through renewable sources, have passive-house standards or higher for all its buildings, choose wood or other materials with low GHG intensity as main building materials, and reduce and find climatefriendly solutions for the mobility of its inhabitants."

The on-site electricity production in Ydalir consists of a district heating plant, PV panels, and 9 combined-heatand-power (CHP) machines fuelled by wood chips with an electric power of $40 \mathrm{~kW}$, a heating power of $100 \mathrm{~kW}$, and assumed 7000 annual operating hours. In addition, Ydalir has signed an agreement with the local district company.
On the basis of the recommendation by Steinmann et al. (2016) to use four-six impact categories to cover most of the variance (84-92\%) in product rankings, five mid-point impact categories are selected: Climate Change, Freshwater Eutrophication, Human Toxicity, Metal Depletion, and Terrestrial Acidification. In addition, the importance of using several climate metrics to give short-lived GHG such as methane the attention they deserve has been stressed and recommended by the UNEP SETAC task force on climate change (Cherubini et al. 2016; Levasseur et al. 2016). On the basis of this recommendation, a climatemetrics sensitivity analysis is conducted by evaluating Climate Change with the global warming caused in three time horizons of 20,100 , and 500 years.

\subsection{Climate mitigation strategies}

The Baseline scenario and the four CMS are described in Table 1. The Baseline scenario depicts the situation at Ydalir without including the ambitious mobility targets. The changes made from the Baseline to each CMS are underscored in Table 1.

The first CMS (CMS 1), Mobility Ydalir, factors in the ambitions set on the mobility patterns at Ydalir. The transport-mode shares are thus changed accordingly. The next three CMS are based on the material efficiency strategies proposed by Hertwich et al. (2019) to reduce GHG emissions associated with buildings, vehicles, and electronics. CMS 2, Increased Lifetimes, is based on a material efficiency strategy that focuses on increasing the lifetime of buildings and vehicles. The building lifetime is set to 100 years and is closer to a more representative building lifetime of 125 years defined by Sandberg et al. (2016) for Norwegian buildings. The 60 years building lifetime is set according to the standard NS 3720:2018—Methods for greenhouse gas calculations for buildings (in Norwegian) (NS 2018)). The vehicle lifetime is increased by $25 \%$. In CMS 3, Better Use, the dwelling and passenger cars are better used by means of reducing the residential dwellings size by $25 \%$ and increasing the passenger load of the passenger cars by $25 \%$. The $25 \%$ increase or reduction levels are chosen as examples, without examining whether this is desired or achievable, but to examine the effects of such increase or reduction levels. In CMS 4, Combined Strategies, all the afford-mentioned CMSs are combined.

Please notice that, although the changes are underscored, their subsequent influence on other parameters is not 
Table 1 Description of the Baseline scenario and the four climate mitigation strategies (CMS)

\begin{tabular}{|c|c|c|c|c|c|c|}
\hline & & \multirow[b]{2}{*}{ Baseline } & \multicolumn{4}{|c|}{ Climate mitigation strategies } \\
\hline & & & Mobility_Ydalir & Increased Lifetimes & Better Use & $\begin{array}{l}\text { Combined } \\
\text { Strategies }\end{array}$ \\
\hline & Units & & CMS 1 & CMS 2 & CMS 3 & CMS 4 \\
\hline \multicolumn{7}{|l|}{ Buildings } \\
\hline \# Residential unit & unit & 1000 & 1000 & 1000 & 1000 & 1000 \\
\hline \# Kindergarten & unit & 1 & 1 & 1 & 1 & 1 \\
\hline \# School & unit & 1 & 1 & 1 & 1 & 1 \\
\hline Lifetime & year & 60 & 60 & $\underline{100}$ & 60 & $\underline{100}$ \\
\hline Residential unit & $\mathrm{m}^{2} /$ unit & 100 & 100 & 100 & $\underline{75}$ & $\underline{75}$ \\
\hline Kindergarten & $\mathrm{m}^{2} /$ unit & 2140 & 2140 & 2140 & 2140 & 2140 \\
\hline School & $\mathrm{m}^{2} /$ unit & 6474 & 6474 & 6474 & 6474 & 6474 \\
\hline Inhabitants & pers / unit & 2.5 & 2.5 & 2.5 & 2.5 & 2.5 \\
\hline Share inhabitants $20-60$ years & $\%$ & $61 \%$ & $61 \%$ & $61 \%$ & $61 \%$ & $61 \%$ \\
\hline Share inhabitants $0-19$ years and $67-80+$ years & $\%$ & $39 \%$ & $39 \%$ & $39 \%$ & $39 \%$ & $39 \%$ \\
\hline Energy use (Residential) & $\mathrm{kWh} /\left(\mathrm{m}^{2} \cdot\right.$ year $)$ & 78 & 78 & 78 & 78 & 78 \\
\hline Heat & $\mathrm{kWh} /\left(\mathrm{m}^{2} \cdot\right.$ year $)$ & 45 & 45 & 45 & 45 & 45 \\
\hline Electricity & $\mathrm{kWh} /\left(\mathrm{m}^{2} \cdot\right.$ year $)$ & 33 & 33 & 33 & 33 & 33 \\
\hline Energy use (Non-residential) & $\mathrm{kWh} /\left(\mathrm{m}^{2} \cdot\right.$ year $)$ & 109 & 109 & 109 & 109 & 109 \\
\hline Heat & $\mathrm{kWh} /\left(\mathrm{m}^{2} \cdot\right.$ year $)$ & 36 & 36 & 36 & 36 & 36 \\
\hline Electricity & $\mathrm{kWh} /\left(\mathrm{m}^{2} \cdot\right.$ year $)$ & 73 & 73 & 73 & 73 & 73 \\
\hline Total Heat & GWh/year & 4.8 & 4.8 & 4.8 & 3.7 & 3.7 \\
\hline Total Electricity & GWh/year & 3.9 & 3.9 & 3.9 & 3.1 & 3.1 \\
\hline \multicolumn{7}{|l|}{ On-site infrastructure } \\
\hline Electricity & $\mathrm{kWh} /$ year & 0.3 & 0.3 & 0.3 & 0.3 & 0.3 \\
\hline \multicolumn{7}{|l|}{ Mobility } \\
\hline Travel distance, inhabitants $20-60$ years & $\mathrm{km} /$ day & 36.7 & 36.7 & 36.7 & 36.7 & 36.7 \\
\hline $\begin{array}{l}\text { Travel distance, inhabitants } 0-19 \text { years and } \\
67-80+\text { years }\end{array}$ & $\mathrm{km} /$ day & 20 & 20 & 20 & 20 & 20 \\
\hline \multicolumn{7}{|l|}{ Transport mode shares } \\
\hline Foot & $\%$ & $4 \%$ & $\underline{4 \%}$ & $4 \%$ & $4 \%$ & $\underline{4 \%}$ \\
\hline Bike & $\%$ & $10 \%$ & $15 \%$ & $10 \%$ & $10 \%$ & $15 \%$ \\
\hline Passenger car & $\%$ & $67 \%$ & $\underline{50 \%}$ & $67 \%$ & $67 \%$ & $\underline{50 \%}$ \\
\hline Public transportation, bus & $\%$ & $15 \%$ & $\underline{20 \%}$ & $15 \%$ & $15 \%$ & $\underline{20 \%}$ \\
\hline Public transportation, train & $\%$ & $4 \%$ & $11 \%$ & $4 \%$ & $4 \%$ & $11 \%$ \\
\hline Passenger load, car & passenger/car & 1.8 & 1.8 & 1.8 & $\underline{2.25}$ & $\underline{2.25}$ \\
\hline Electric cars, electricity use & GWh/year & 0.24 & 0.18 & 0.24 & 0.19 & 0.14 \\
\hline Passenger cars, lifetime & $\mathrm{km}$ & 180000 & 180000 & $\underline{225000}$ & 180000 & $\underline{225000}$ \\
\hline \multicolumn{7}{|l|}{ On-site energy production } \\
\hline PV panels, installed capacity & $\mathrm{m}^{2} /$ residential unit & 18 & 18 & 18 & 18 & 18 \\
\hline PV panels, efficiency ${ }^{\mathrm{a}}$ & $\mathrm{kWh} /\left(\mathrm{m}^{2} \cdot\right.$ year $)$ & 140 & 140 & 140 & 140 & 140 \\
\hline PV panels, annual electricity production ${ }^{\mathrm{a}}$ & GWh/year & 2.52 & 2.52 & 2.52 & 2.52 & 2.52 \\
\hline CHP, electricity, Annual production ${ }^{\mathrm{b}}$ & GWh/year & 2.5 & 2.5 & 2.5 & 2.5 & 2.5 \\
\hline Electricity, total annual production & GWh/year & 5.02 & 5.02 & 5.02 & 5.02 & 5.02 \\
\hline CHP, heat, annual production & GWh/year & 6.3 & 6.3 & 6.3 & 6.3 & 6.3 \\
\hline District heat, annual production & GWh/year & 5.5 & 5.5 & 5.5 & 5.5 & 5.5 \\
\hline Heat, total annual production & GWh/year & 11.8 & 11.8 & 11.8 & 11.8 & 11.8 \\
\hline \multicolumn{7}{|l|}{ Surplus energy } \\
\hline Heat & GWh/year & 7.0 & 7.0 & 7.0 & 8.1 & 8.1 \\
\hline Electricity ${ }^{\mathrm{a}, \mathrm{b}}$ & GWh/year & 0.6 & 0.6 & 0.6 & 1.4 & 1.5 \\
\hline
\end{tabular}


Table 1 (continued)

${ }^{a}$ in 2021 followed by an efficiency increase of $20 \%$ in 2050

${ }^{b}$ in 2021 followed by an efficiency increase of $10 \%$ in 2050

highlighted. For instance, a reduction in the size of the residential unit in CMS 3 and CMS 4 induces a decrease of the total annual heat and electricity requirements because the energyuse intensity given in $\left(\mathrm{kWh} /\left(\mathrm{m}^{2}\right.\right.$.year $\left.)\right)$ is held constant.

The on-site production and surplus energy are snapshots taken at the beginning of the POA in 2021. Their evolution over time until the end of the POA is given in the supplementary material.

\section{Results}

In this section, the yearly results are first presented for the Baseline scenario in Fig. 1. Then, the cumulated results of the Baseline scenario and the four CMS are presented in
Fig. 2. Finally, the results of the sensitivity of the choice of climate metrics is presented in Fig. 3. All the result datapoints are given in the supplementary material.

At the start of the POA in 2021, the shares of the different sub-systems to the total environmental impacts vary across the impact categories. For Climate Change, Mobility $\mathrm{O}$ comes first with $67 \%$ followed by Mobility $\mathrm{M}$ with $12 \%$, Buildings $\mathrm{M}$ with $12 \%$, On-Site Energy with $7 \%$, and Infrastructure with $4 \%$ and 3\% for the Mobility-Related and On-Site Infrastructure, respectively. The emission gains are of 5\%. For Freshwater Eutrophication, Mobility comes first as well, but this time with Mobility M with a share of $45 \%$ followed by On-Site Energy with 23\%, Building $\mathrm{M}$ with $16 \%$, Mobility $\mathrm{O}$ with $7 \%$, and Infrastructure
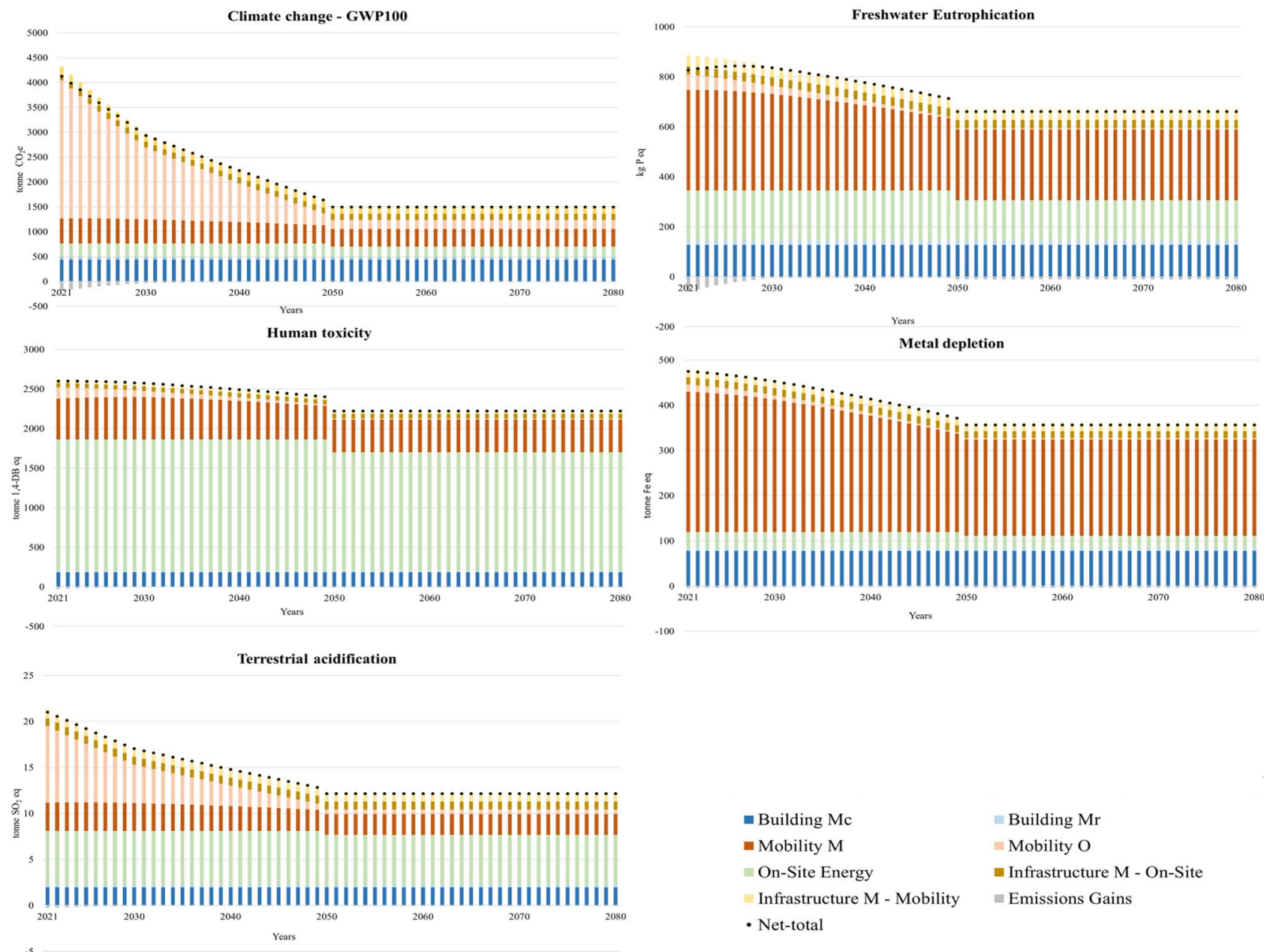

Fig. 1 Yearly environmental midpoint indicator results and their sources for the Baseline scenario 


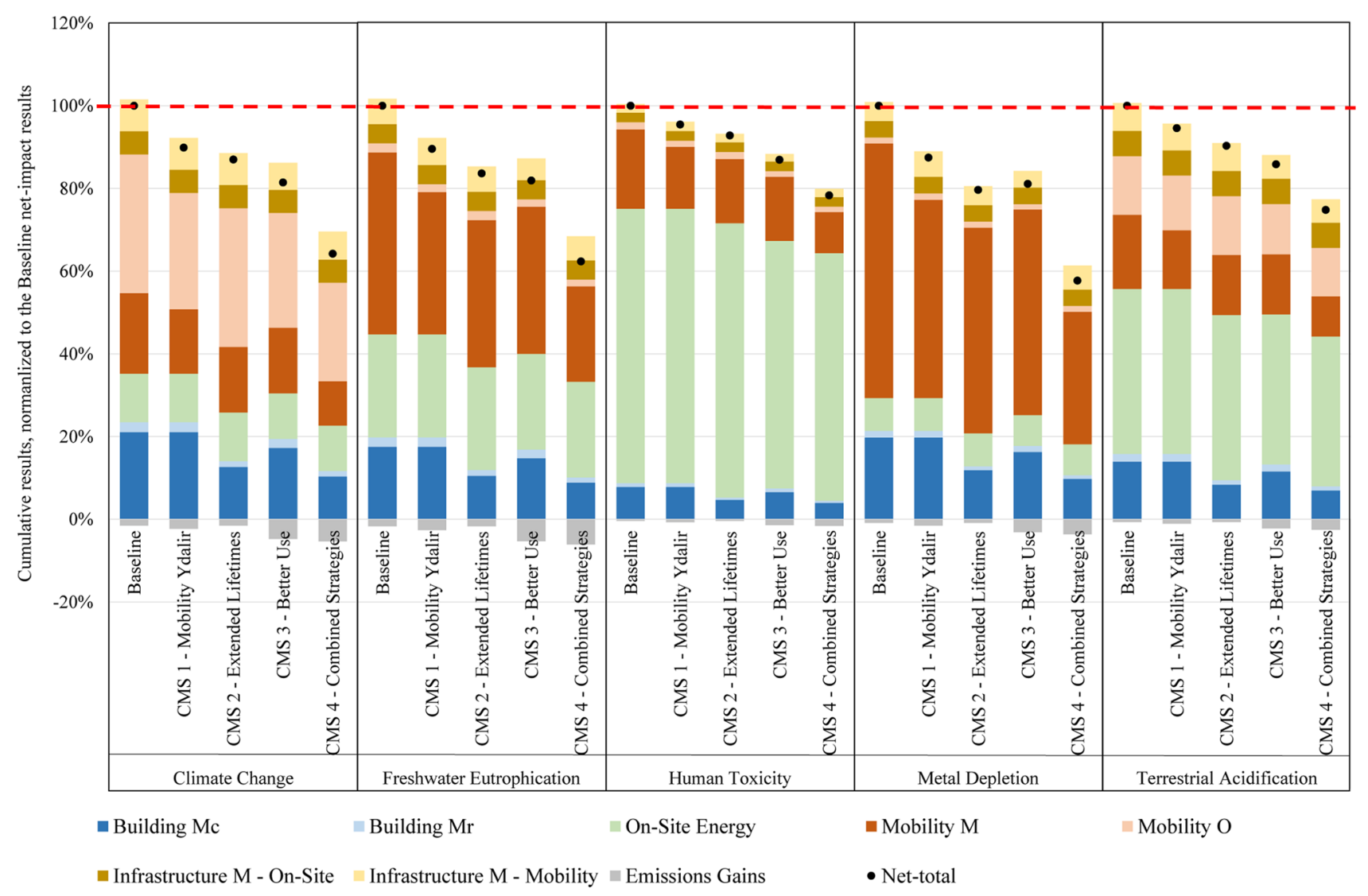

Fig. 2 Cumulative results over the period of analysis, for each climate mitigation strategy (CMS) and each environmental impact category, normalized relative to the Baseline net-impact results

with 5\% and 4\% for the Mobility-Related and On-Site Infrastructure, respectively. The emission gains are marginal and of less than 1\%. For Human Toxicity, On-Site Energy comes first with most of the environmental impact with $64 \%$ followed by Mobility M with $20 \%$, Building M with $8 \%$, Mobility $\mathrm{O}$ with 5\%, and Mobility-Related and On-Site Infrastructure both with a share of $2 \%$. The emission gains are of $1 \%$. For Metal Depletion, the majority of the environmental impact comes from Mobility $\mathrm{M}$ with a share of $65 \%$ followed by Building M with $17 \%$, On-Site Energy with 7\%, Mobility O with 3\%, and Infrastructure with $4 \%$ and $3 \%$ for the Mobility-Related and On-Site Infrastructure, respectively. The emission gains are of 1\%. For Terrestrial Acidification, Mobility O holds the highest share with $40 \%$ followed by On-Site Energy with $28 \%$, Mobility $\mathrm{M}$ with $15 \%$, Building $\mathrm{M}$ with $10 \%$, and Infrastructure with 5\% and $4 \%$ for the Mobility-Related and On-Site Infrastructure, respectively. The emission gains are of $1 \%$.

Two patterns are observed when comparing the distribution of the sub-systems at the beginning and at the end of the POA. The first pattern is observed for Climate Change and Terrestrial Acidification where the material-related sub-systems M take over the operational sub-systems $\mathrm{O}$ induced by the electrification based on energy source of the mobility. The second pattern is valid for Freshwater Eutrophication, Human Toxicity, and Metal Depletion where the distribution patterns and order remain pretty much the same.

The yearly absolute environmental impacts of the end of the POA are decreased compared to the beginning of the POA in all the impact categories. The highest decrease of $64 \%$ is attributed to Climate Change followed by a decrease of $42 \%$ for Terrestrial Acidification, 25\% for Metal Depletion, 24\% for Freshwater Eutrophication, and $14 \%$ for Human Toxicity.

Those decreases are induced by the better assumed efficiencies in the production processes of the main materials, in addition to an increased reuse and use of recycled materials over time. Those improvements are reflected in the environmental impacts intensities that are decreased over time. The improvements explain counter-intuitive results such as Mobility $\mathrm{M}$ that decreases over time despite the penetration of a high share of electric vehicles that haveas per today-a higher environmental impact of 56-88\% across the assessed impact categories in their production than their conventional counterparts. 


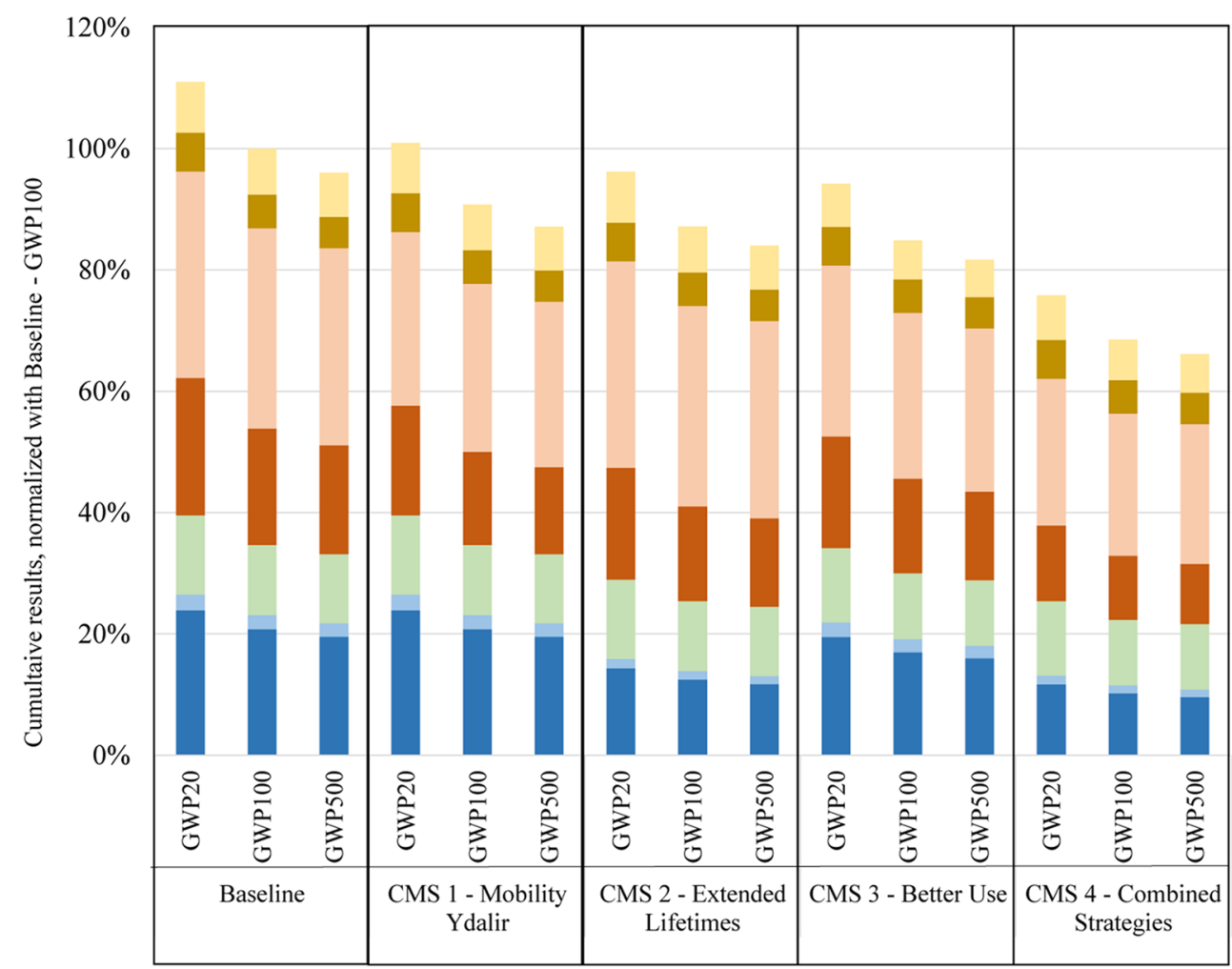

Infrastructure M - Mobility

- Infrastructure M - On-site

Mobility $\mathrm{O}$

- Mobility M

$\square$ On-site energy

Building $\mathrm{Mr}$

- Building Mc

Fig. 3 Cumulative results excluding emissions gains, normalized with Baseline-GWP 100, computed with three different climate metrics with 20-, 100-, and 500-year time horizon; GWP = global warming potential

The cumulative results over the POA are presented in Fig. 2 for the Baseline scenario and the four CMS. Environmental co-benefits are shown across all the impact categories and CMS and are of 5-13\% for CMS 1 Mobility Ydalir, 7-20\% for CMS 2 Extended Lifetimes, 13-19\% for CMS 3 Better Use, and of 22-42\% for CMS 4 Combined Strategies. Interestingly, the highest environmental benefits of $42 \%$ for CMS 4 are not found for Climate Change but for Metal Depletion.

For CMS 1 Mobility Ydalir, the environmental benefits induced by the introduction of mobility patterns that reduce the use of passenger cars and promote the use of public transportation, biking, and walking can be found in all the mobility-related sub-systems. The climate and environmental co-benefits range from $4-14 \%$ for Mobility M, 1-5\% for Mobility O, and $0.1-4 \%$ for Infrastructure M-Mobility. Whereas environmental benefits can be found in all the impact categories for the operational phases (Mobility O), the environmental benefits are mainly concentrated for Metal Depletion for the embodied emissions in materials (Mobility $\mathrm{M}$ and Infrastructure M- Mobility).

For CMS2 Extended Lifetime, the extension of the lifetime of the passenger cars and building both by $25 \%$ induces environmental benefits that can be found in the sub-systems Mobility M with 3-9\% and Building M with
3-12\%. The lowest environmental befits are attributed to Terrestrial Acidification and Human Toxicity. On the other hand, the highest environmental benefits are attributed to Metal Depletion for both Mobility M and Building $M$ induced by a decrease in metal use to fulfill the mobility needs of the inhabitants over the POA as well as a discounting of the stock of metals in the building over a longer time period. High environmental benefits of $9 \%$ are also shown for Climate Change, mainly induced by a longer discounting period of the construction materials in the building due to building lifetime extension.

For CMS 3 Better Use, the reduction of $25 \%$ of the dwelling size combined with a better use of the passenger cars induced by an increase of the passenger load by $25 \%$ show environmental benefits across all the impact categories and sub-systems except for Infrastructure M-On-Site that is not affected by those measures. In descendant order, the environmental benefits are of $4-12 \%$ for Mobility M, 1-7\% for On-Site Energy, 0.2-6\% for Mobility O, 1-4\% for Building M, 1-3\% for Emission Credits, and 0.3-1\% for Infrastructure M-Mobility.

The combination of the three afford-mentioned CMS leads to further environmental benefits of a total of $22-42 \%$. As it is the case for CMS 3, environmental benefits are shown across all the impact categories and 
sub-systems except for Infrastructure M-On-Site that is not affected by any of those measures. In descendant order, the environmental benefits are of 8-29\% for Mobility M, 4-12\% for Building M, $0.1-10 \%$ for Mobility O, 1-7\% for On-Site Energy, 0.1-4\% for Emission Credits, and around $1 \%$ for Infrastructure M-Mobility.

The cumulative results are presented for three different climate metrics to test the influence that the time horizon of the climate metric has on the results. All the results are normalized to the results of the cumulated results of the Baseline computed with a time horizon of 100 years.

Compared to using global warming potential (GWP) 100 to measure Climate Change, the cumulative results over the POA vary by $-2-(-) 4 \%$ to $7-11 \%$ when measuring Climate Change with a climate metric that accounts for the global warming that cumulates over a time period of 500 years (GWP500) and 20 years (GWP20), respectively.

The M sub-systems are the most affected by a use of another time horizon to measure global warming to quantify potential climate change. It is the methane released when extracting and producing the fossil fuels used in the production of those materials constituting the materials M subsystems that causes most of the variations. On the other hand, the operational $\mathrm{O}$ sub-systems are less affected; indeed, they are already decarbonized because of the use of renewable energy locally produced to supply the energy need of the buildings and the electric cars.

\section{Discussion}

\subsection{Benchmarking with previous studies}

Normalized with the total number of inhabitants, our yearly results vary between 1.0-1.6 tonnes $\mathrm{CO}_{2} \mathrm{e} /$ pers at the beginning of the POA in 2021 and between $0.38-0.60$ tonnes $\mathrm{CO}_{2} \mathrm{e} /$ pers from 2050 and until the end of the POA. Our study has the particularity to assess buildings with lowenergy-use standard that are in addition fed by renewable energy. Thus, the environmental impacts stemming from the operational phase of the buildings are drastically decreased. Therefore, our result are found in the lower range of the yearly results found in the literature of $0.6-8.6$ tonnes $\mathrm{CO}_{2} \mathrm{e} /$ pers reviewed by Lotteau et al. (2015).

For similar latitudes, high-energy standards on houses and mobility stock composition, the yearly results of -0.04-2.64 tonnes $\mathrm{CO}_{2} \mathrm{e}$./pers (Lausselet et al. 2019, 2020a) found previously by using the model further developed in this study align well with our results. For a Swiss municipality where an average energy use in buildings is applied, Saner et al. (2013) found a yearly mean value of 4.30 tonnes $\mathrm{CO}_{2} \mathrm{e} . /$ pers, slightly higher than our results, but still in the same order of magnitude. When including the total household requirements by including, for example, food and services, Ivanova et al. (2016) found a value of 10.3 tonnes $\mathrm{CO}_{2} \mathrm{e} . /$ pers. for Norway, for a world average of 3.4 tonnes $\mathrm{CO}_{2}$ eq./ pers. (in 2007).

When comparing the share of the different sub-systems, our LCA model yields results similar to those reported in the literature. The mobility shares (16-53\%) are higher than the shares assigned to building (9-23\%) across all the impact categories in accordance with Bastos et al. (2016) who found user transportation to account for the largest share of emissions, ranging from 51 to $57 \%$. The shares of $5-13 \%$ of infrastructure (mobility-related and on-site) across the impact categories align well with the shares of the GHG emissions related to infrastructures $16-22 \%$ of the total found by Stephan et al. (2013).

A comprehensive overview of the potential of CMS to mitigate vehicle emissions under a vast range of conditions is presented by Wolfram et al. (2020). A more intensive use is found to yield reduction of $25 \%$ comparable to our range of 13-19\% found for CMS 3 Better Use. The highest cut of $29-57 \%$ is found when combining their strategies, similar to our range of $22-42 \%$ for CMS 4 Combined Strategies. CMS are applied in order to reduce the climate impact of the buildings of a nZEN in the early planning stages by Lausselet et al. (2020b) with a better use that yields a reduction of $25 \%$ and the combination of CMS that yields the highest reduction of $44 \%$.

\subsection{Uncertainties, limitations, and future work}

The use of several climate metrics has shed light on the use of fossil fuels in the production value chains of the materials used to provide the mobility services and shelters to the inhabitants of Ydalir. A recent study by Hmiel et al. (2020) showed methane emissions from fossil fuels to be $25-40 \%$ higher than earlier estimates suggested. The fossilfueled value chains are thus likely responsible for an even larger proportion of recent climate change than previously thought. Decarbonizing the power sector has direct implications for other sectors (Wiebe 2018), and the global warming caused by short-term GHG such as methane should be fully captured. The importance of using several climate metrics to consider short-lived GHG such as methane as they deserve has been stressed and recommended by the UNEP SETAC task force on climate change (Cherubini et al. 2016; Levasseur et al. 2016). This recommendation is especially valid as long as a significant number of global value chains have not replaced their upstream use of fossil fuels by renewable-energy sources.

A yearly energy balance is used. On the other hand, a higher resolution could be achieved by using an hourly energy profile that would consider that a higher quantity of $\mathrm{PV}$ electricity is produced during daytime and a large part 
of the consumption occurs at night when there is no production. Accounting for the temporal variation of electricity production and use in LCAs of energy-efficient buildings is crucial because the use of yearly energy profiles can lead to overestimations of the surplus energy and subsequent emission credits (Roux et al. 2016). To provide a clear scientific background regarding the hourly GHG intensity of one $\mathrm{kWh}$ of produced electricity in order to provide a decision support tool to fully exploit the advantages of a future smart grid is crucial (Clauß et al. 2018; Messagie et al. 2014; Vandepaer and Gibon 2018; Vandepaer et al. 2019b). Implementing energy storage and vehicle-to-grid concepts then also becomes relevant (Kelly et al. 2015; Munkhammar et al. 2015; Vandepaer et al. 2019a).

Energy storage is a crucial parameter of nZENs because they base their energy supply on renewable energy and thus, by definition, intermittent energy sources. The potential to store, peak-shave, and thus improve the match between energy production and use should be further investigated. Furthermore, electric cars represent a significant share of the mobility parc in a nZEN, and the opportunities to use the electric mobile parc as a battery to store and further reinject the stored energy by using vehicle-to-grid technologies should be assessed. But, to our knowledge, there are no LCA studies that use hourly energy profiles to assess the interaction between buildings, electric vehicles, in particular their battery, and the potential of the latter to temporally store and supply the electricity produced on-site back when appropriate.

The model scenarios of future development paths can reveal how the environmental performance of a nZEN project is influenced by parameters describing alternative future developments. Predicting how such parameters will evolve has substantial uncertainty. A global sensitivity analysis such as a variance-based sensitivity analysis (Saltelli et al. 2010) could be performed to capture such effects. Such a "global sensitivity analysis" could be based on the pedigree approach undertaken by, for example, Ecoinvent (Frischknecht et al. 2016). In a Pedigree approach, each input and output of the life-cycle inventories is assessed according to six characteristics: reliability, completeness, temporal correlation, geographic correlation, further technological correlation, and sample size. The Pedigree approach could be expanded to the foreground processes defined in the LCA model developed in this study. Also, the LCA results will gain in robustness if the Pedigree approach is extended along all the life-cycle phases, including the impact assessment phase.

Environmental co-benefits have been shown for all the CMS and impact categories. Those co-benefits are inherent to the nature of the CMS because they are based on material efficiency strategies that are deemed by their essence to reduce the pressure on the environment. The other reason is the constraint on the functional unit to be fulfilled across the CMS. If the functional unit had been "spend the money invested to fulfil the housing, school, kindergarten, and mobility needs of the 2500 inhabitants of Ydalir over a 60-year time period," a potential rebound effect could potentially have had negative environmental co-benefits, depending on how the financial left-overs saved in CMS 1-4 would have been spent. Also, a functional unit measured in monetary terms will allow to measure the cost-effectiveness of the proposed CMSs and thus measure both their environmental and economic sustainability.

When assessing our prospective CMS, energy-efficiency improvements along the production chains have been factored in by the use of coefficients that reflect the shift from fossil fuels to a more circular economy based on renewableenergy sources. In future studies, a more systematic analysis of potential and expected improvements in material production, manufacturing, and transport is needed. The environmental impact intensities have been assessed and decreased on a model sub-system level. Ideally, the resolution should be higher and the trajectory of each material over time should be assessed and projected individually. This could be achieved by allocating an individual material coefficient to each material environmental intensity at different points in time. Neglecting such improvements could result in underestimating the environmental benefits of climate mitigation policies (Hertwich et al. 2015). Also, only current available technologies are considered. But, over the POA of 60 years considered in this study, new disruptive technologies will most probably come into play e.g. hydrogen vehicles or autonomous vehicles for the mobility sub-systems.

In the same manner that only current available technologies are considered, only current climate conditions are assumed. Climate is changing rapidly and leads to climate extremes at a frequency never seen before (IPCC 2021). The projections indicate a warmer climate in Norway for all seasons, with a greater projected warming for winter than for summer. Temperatures are expected to increase by 1.6-6.7 ${ }^{\circ} \mathrm{C}$ and the number of "warm days" $\left(>20{ }^{\circ} \mathrm{C}\right)$ is expected to triple by the end of the century (Hanssen-Bauer et al. 2017). Neither temperature increases over time nor climate extremes are included in the scenarios. Temperature increases will lead to a lesser need for heating in the winter and possible use of air-conditioning in the summer. In terms of modelling, climate extremes will translate in anything from shorter renovation and/or replacement periods of part of the model sub-systems to the replacement of the whole building stock, infrastructure, and vehicle fleet.

The Norwegian electricity production mix is already highly based on renewables with a share of $95 \%$ hydropower and 2.6\% wind power (Statistics Norway 2019). Renewable electricity produced locally by PV has been the favored method of electricity production for nZENs. Exploiting local 
wind, biomass and geothermal sources are other available alternative renewable energy production pathways that will have to be examined based on their environmental profile, costs, and acceptance. But, by further producing renewable energy on a neighbourhood scale, nZENs may play a role in the decarbonization of the European energy mix by (1) sending their surplus energy to the grid, with potential for export outside Norway and (2) liberating electricity from hydropower that will substitute more carbon-rich electricity or fuels generated elsewhere, such as in the strive for electrification of road transport. This is especially true per today with a European energy system relying extensively on fossil fuels but will change over time along with the decarbonization of the European energy system.

The construction of new neighbourhoods can potentially lead to changes in land use at a scale that influences the local balance of carbon storage in soil and vegetation. This might in particular be the case when bog areas, or agricultural and forestry land are developed for urbanization purposes. Those aspects should be better assessed when new neighbourhoods and settlements are being planned. The matching of the foreground processes (e.g., a building in a nZEN) with the environmental stressors that are further addressed in terms of characterization factors should be done in such a way that the full potential effects of the construction of nZEN are captured, on-site and along the material production value chains.

\subsection{Policy implications}

The CMS presented in this study clearly showed the combination of different measures across several layers at different points in time to best mitigate climate change and to provide environmental co-benefits.

At the early planning stages, the focus should be set on finding incentives that will promote dwellings of reasonable sizes. To avoid the neutralization of those dwellingsize incentives, dwelling sizes should be measured not only by dwelling but also by inhabitants. As of today, dwelling sizes are not regulated. A typical case where dwelling sizes would reduce could be in an urban area where the pressure on prices is high and could constrain and decrease the dwelling sizes. For promoters to be willing to build and promote dwelling of smaller sizes, incentives should be in place to create markets for those dwellings of reduced sizes to be sold. Promising recent trends on designing buildings where part of the space is shared for given activities have appeared (Fyrstikkbakken 2021). Those initiatives should be actively promoted because they hold the potential to help pave the way for reducing the floor area per inhabitant.

Whereas the environmental impact caused by the operational phases of the buildings and mobility-fleet are drastically reduced in nZENs thanks to the use of lowenergy-use standards and the production of locally renewable energy that supply the buildings and the electric passenger vehicle fleet, the use of fossil fuels along the material value chains is still highly present. Thus, incentives and standards should promote not only the decarbonization of the operational phases but also of the material value chains, in-and out-land. This calls for a consumer accounting perspective.

Over time, a culture of car- and ride-sharing should be encouraged. Whereas the former will reduce the pressure on the use of resources mainly by diminishing the in-use stock of metals, the latter will have climate and environmental co-benefits in several other aspects such as an improved airquality, traffic noise, and congestion.

Per today, nZENs only represent a marginal share of national building stocks that also contain buildings with less strict energy-use standards. When deploying strategies to renovate national building stocks, the opportunity to reshape dwellings into dwellings of smaller sizes should be assessed in favor of a sole focus on nZEB standards. When deploying strategies to renovate the buildings of Ydalir, the future population demographic should be assessed, and if applicable, measures to reshape dwellings sizes could be incentivized.

Another aspect is an enhanced digitalization that would allow to overcome a binary relation between a single dwelling, car, and PV owner to several dwelling, car, and PV owners. This new type of model will allow to interconnect all the sub-elements of a nZEN and embrace a systemic approach that will allow for the high- and low-hanging fruits to be picked when drawing CMS.

Climate-change mitigation opportunities are broader than the ones proposed in this study that focus on housing and mobility needs only. For instance, Lekve Bjelle et al. (2018) have shown the beneficial effects of flying less or modifying food diets. On average, households-via their consumption in terms of material, water, and land-use requirements-are responsible for more than $60 \%$ of global GHG emissions and between 50 and $80 \%$ of total land, material, and water use (Hertwich and Peters 2009; Ivanova et al. 2016). Households thus sit with a tremendous mitigation potential.

LCA results are useful to quantify the pressure on the environment and on the resources induced by human activities. By drawing CMSs as it is the case in this study, LCA results can inform environmental policies on possible pathways to reduce the pressure on the environment and on the resources. LCA results at a certain point in time represent the current best available knowledge and practice. LCA results should thus not be seen as static, but rather evolutionary and should be updated whenever better knowledge is available (UNEP and Setac 2016). In addition, intrinsic differences exist between the boundary conditions and related assumptions between the impact assessment methods used 
in LCA and other frameworks. This is for example the case for human toxicity. Whereas a LCA framework focuses on the most likely range of exposure and harm for the median individual in a given human population, a human health risk assessment framework will ensure that an actual risk has not been underestimated (UNEP and SETAC 2019).

But, to achieve net-zero-emission, the previously mentioned strategies will most probably have to be supplemented by $\mathrm{CO}_{2}$ removal methods (e.g., afforestation, agricultural practices that sequester carbon in soils, bio-energy with carbon capture, and storage, and direct air capture when combined with storage) in order to provide negative emissions according to the IPCC (2018).

\section{Conclusion}

Demand-side material efficiency strategies are complementary to those obtained through the decarbonization of our energy system and may offer substantial GHG mitigation potentials. To assess their combination, we use LCA to assess the environmental potential co-benefits and trade-offs of a nZEN in the early planning stages and develop CMS to come with recommendations on when the different CMS must be in place.

When deploying CMS, environmental co-benefits of 5-20\% for individual CMS and of $22-42 \%$ for combined CMS are shown across the impact categories. The highest environmental benefits of $42 \%$ are found for Metal Depletion, shedding light on the close interlink between climate change mitigation and reduced pressure on resource use.

The CMS presented in this study clearly showed the combination of different measures across several layers at different points in time to best mitigate climate change and to provide the highest environmental co-benefits. At the early planning stages, the focus should be set on finding incentives that will promote dwellings of reasonable sizes, preferably around 25\% smaller than the average size, measured per inhabitant. In addition, incentives to decarbonize the material value chains should be promoted, in- and out-land. Over time, a culture of car- and ride-sharing should be encouraged. Whereas the former will reduce the pressure on the use of resources by diminishing the in-use stock of metals, the latter will have climate and environmental co-benefits in several other aspects such as an improved air-quality, traffic noise, and congestion. When deploying strategies to renovate national building stocks, the opportunity to reshape dwellings into dwellings of smaller sizes should be assessed in favor of a sole focus on nZEB standards.

Future LCA studies on nZENs should better account for the temporal variation of electricity production and use by using hourly energy profiles. Also, the potential of energy storage and vehicle-to-grid concepts to store, peak-shave, and thus improve the match between energy production and use should be further investigated.

Supplementary information The online version contains supplementary material available at https://doi.org/10.1007/s11367-021-01973-3.

Acknowledgements The authors gratefully acknowledge the support from the Research Council of Norway and several partners through the Research Centre on Zero Emission Neighborhoods in Smart Cities (FME ZEN).

Funding Open access funding provided by NTNU Norwegian University of Science and Technology (incl St. Olavs Hospital-Trondheim University Hospital).

Open Access This article is licensed under a Creative Commons Attribution 4.0 International License, which permits use, sharing, adaptation, distribution and reproduction in any medium or format, as long as you give appropriate credit to the original author(s) and the source, provide a link to the Creative Commons licence, and indicate if changes were made. The images or other third party material in this article are included in the article's Creative Commons licence, unless indicated otherwise in a credit line to the material. If material is not included in the article's Creative Commons licence and your intended use is not permitted by statutory regulation or exceeds the permitted use, you will need to obtain permission directly from the copyright holder. To view a copy of this licence, visit http://creativecommons.org/licenses/by/4.0/.

\section{Reference}

Ajanovic A (2015) The future of electric vehicles: Prospects and impediments Wiley Interdisciplinary Reviews. Energy and Environment 4:521-536. https://doi.org/10.1002/wene.160

Allwood JM, Ashby MF, Gutowski TG, Worrell E (2011) Material Efficiency: A White Paper Resour Conserv Recycl 55:362-381. https://doi.org/10.1016/j.resconrec.2010.11.002

Arvesen A, Luderer G, Pehl M, Bodirsky BL, Hertwich EG (2018) Deriving Life Cycle Assessment Coefficients for Application in Integrated Assessment Modelling Environ Model Softw 99:111125. https://doi.org/10.1016/j.envsoft.2017.09.010

Bastos J, Batterman SA, Freire F (2016) Significance of mobility in the life-cycle assessment of buildings. Building Research and Information 44:376-393. https://doi.org/10.1080/09613218.2016. 1097407

Cherubini $F$ et al (2016) Bridging the gap between impact assessment methods and climate science. Environ Sci Policy 64:129-140. https://doi.org/10.1016/j.envsci.2016.06.019

Clauß J, Stinner S, Solli C, Lindberg KB, Madsen H, Georges L (2018) A generic methodology to evaluate hourly average $\mathrm{CO}<\mathrm{inf}>2<1$ inf $>$ intensities of the electricity mix to deploy the energy flexibility potential of Norwegian buildings Proc 10th Int Conf Syst Simul Build, Liege, Belgium:1-19

Cox B, Mutel CL, Bauer C, Mendoza Beltran A, Van Vuuren DP (2018) Uncertain Environmental Footprint of Current and Future Battery Electric Vehicles. Environ Sci Technol 52:4989-4995. https://doi.org/10.1021/acs.est.8b00261

Ecoinvent Centre (2015) Ecoinvent 3.2. Swiss Centre for Life Cycle Inventories. http://www.ecoinvent.org/support/documents-andfiles/information-on-ecoinvent-3/information-on-ecoinvent-3. html. Accessed 24.082016 
Ellingsen LAW, Singh B, Strømman AH (2016) The size and range effect: Lifecycle greenhouse gas emissions of electric vehicles Environmental Research Letters 11 https://doi.org/10.1088/17489326/11/5/054010

ESU, IFEU (2008) New Energy Externalities Developments for Sustainability (NEEDS) - LCA of background processes.

European Commission (2010) Energy Performance of Buildings Directive, Directive 2010/31/EU.

European Committee for Standardization (2012) EN 15978:2011, Sustainability of construction works - assessment of environmental performance of buildings - calculation method. Brussels, Belgium

Finnveden G et al (2009) Recent developments in Life Cycle Assessment. J Environ Manage 91:1-21. https://doi.org/10.1016/j.jenvman.2009. 06.018

Fridstrøm L, Østli V (2016) Vehicle fleet forecasts based on stock-flow modeling (in Norwegian). Institute of Transport Economics,

Frischknecht R et al (2016) Global guidance on environmental life cycle impact assessment indicators: progress and case study Int J Life Cycle Assess 21:429-442. https://doi.org/10.1007/ s11367-015-1025-1

Fufa SM, Dahl Schlanbusch R, Sørnes K, Inman M, Andresen I (2016) A Norwegian ZEB Definition Guideline. Sintef, NTNU,

Fyrstikkbakken (2021). https://fyrstikkbakken14.no/.

Gibon T, Arvesen A, Hertwich EG (2017a) Life cycle assessment demonstrates environmental co-benefits and trade-offs of lowcarbon electricity supply options. Renewable Sustainable Energy Rev 76:1283-1290. https://doi.org/10.1016/j.rser.2017.03.078

Gibon T, Hertwich EG, Arvesen A, Singh B, Verones F (2017b) Health benefits, ecological threats of low-carbon electricity Environmental Research Letters 12 https://doi.org/10.1088/1748-9326/aa6047

Goedkoop M, Heijungs R, Huijbregts MAJ, Schryver AD, Struijs J, Zelm RV (2013) ReCiPe 2008. Dutch Ministery of the Environment, The Hague, Netherlands

Hanssen-Bauer I et al. (2017) Climate in Norway 2100- a knowledge base for climate adaptation vol NCCS report no. 1/2017

Hellweg S, Milà i Canals L (2014) Emerging approaches, challenges and opportunities in life cycle assessment Science 344:1109-1113 https://doi.org/10.1126/science.1248361

Hertwich EG et al. (2019) Material efficiency strategies to reducing greenhouse gas emissions associated with buildings, vehicles, and electronics - A review Environmental Research Letters 14 https:// doi.org/10.1088/1748-9326/ab0fe3

Hertwich EG et al (2015) Integrated life-cycle assessment of electricitysupply scenarios confirms global environmental benefit of lowcarbon technologies. Proc Natl Acad Sci USA 112:6277-6282. https://doi.org/10.1073/pnas.1312753111

Hertwich EG, Peters GP (2009) Carbon footprint of nations: A global, trade-linked analysis Environmental Science and Technology 43:6414-6420 https://doi.org/10.1021/es803496a

Hmiel B et al. (2020) Preindustrial 14CH4 indicates greater anthropogenic fossil CH4 emissions Nature 578:409-412 https://doi.org/ 10.1038/s41586-020-1991-8

IEA (2020a) World Energy Balances 2020.

IEA (2020b) World Energy Outlook 2020.

IPCC (2018) IPCC, 2018: Summary for Policymakers. In: Global Warming of $1.5^{\circ} \mathrm{C}$. An IPCC special Report on the impacts of global warming of $1.5^{\circ} \mathrm{C}$ above pre-industrial levels and related global greenhouse gas emission pathways, in the context of strengthening the global response to the threat of climate change, sustainable development, and efforts to eradicate poverty [Masson-Delmotte, V., P. Zhai, H.-O. Pörtner, D. Roberts, J. Skea, P.R. Shukla, A. Pirani, W. Moufouma-Okia, C. Péan, R. Pidcock, S. Connors, J.B.R. Matthews, Y. Chen, X. Zhou, M.I. Gomis, E. Lonnoy, T. Maycock, M. Tignor, and T. Waterfield (eds.)]. World Meteorological Organization, Geneva, Switzerland
IPCC (2021) Climate Change 2021: The Physical Science Basis. Contribution of Working roup I to the Sixth Assessment Report of the Intergovernmental Panel on Climate change [Masson-Delmotte, V., P. Zhai, A. Pirani, S. L. Connors, C. Péan, S. Berger, N. Caud, Y. Chen, L. Goldfarb, M. I. Gomis, M. Huang, K. Leitzell, E. Lonnoy, J. B. R. Matthews, T. K. Maycock, T. Waterfield, O. Yelekçi, R. Yu and B. Zhou (eds.)]

Ivanova D, Stadler K, Steen-Olsen K, Wood R, Vita G, Tukker A, Hertwich EG (2016) Environmental Impact Assessment of Household Consumption J Ind Ecol 20:526-536. https://doi.org/ $10.1111 /$ jiec. 12371

Kelly N, Samuel A, Hand J (2015) Testing integrated electric vehicle charging and domestic heating strategies for future UK housing. Energy and Buildings 105:377-392. https://doi.org/10.1016/j. enbuild.2015.07.044

Lausselet C, Borgnes V, Brattebø H (2019) LCA modelling for Zero Emission Neighbourhoods in early stage planning. Build Environ 149:379-389. https://doi.org/10.1016/j.buildenv.2018.12.034

Lausselet C, Ellingsen LAW, Strømman AH, Brattebø H (2020a) A Life-Cycle Assessment Model for Zero Emission Neighborhoods J Ind Ecol 24:500-516. https://doi.org/10.1111/jiec.12960

Lausselet C, Lund KM, Brattebo H (2021) LCA and scenario analysis of a Norwegian net-zero GHG emission neighbourhood: The importance of mobility and surplus energy from PV technologies Building and Environment in a review process

Lausselet C, Urrego JPF, Resch E, Brattebø H (2020b) Temporal Analysis of the Material Flows and Embodied Greenhouse Gas Emissions of a Neighborhood Building Stock J Ind Ecol 25:419-434. https://doi.org/10.1111/jiec.13049

Lekve Bjelle E, Steen-Olsen K, Wood R (2018) Climate change mitigation potential of Norwegian households and the rebound effect J Clean. Prod 172:208-217. https://doi.org/10.1016/j.jclepro. 2017.10.089

Levasseur A et al (2016) Enhancing life cycle impact assessment from climate science: Review of recent findings and recommendations for application to LCA. Ecol Ind 71:163-174. https:// doi.org/10.1016/j.ecolind.2016.06.049

Lotteau M, Loubet P, Pousse M, Dufrasnes E, Sonnemann G (2015) Critical review of life cycle assessment (LCA) for the built environment at the neighborhood scale Building and Environment 93:165-178 https://doi.org/10.1016/j.buildenv.2015.06.029

Majeau-Bettez G, Strømman AH (2016) Documentation for Arda Calculator, version 1.8.3. 2016.

Messagie M et al (2014) The hourly life cycle carbon footprint of electricity generation in Belgium, bringing a temporal resolution in life cycle assessment Applied Energy 134:469-476 https://doi.org/10.1016/j. apenergy.2014.08.071

Munkhammar J, Bishop JDK, Sarralde JJ, Tian W, Choudhary R (2015) Household electricity use, electric vehicle home-charging and distributed photovoltaic power production in the city of Westminster Energy and Buildings 86:439-448 https://doi.org/ $10.1016 / j$.enbuild.2014.10.006

NS (2018) NS 3720:2018 Method for greenhouse gas calculations for buildings.

Pehl M, Arvesen A, Humpenöder F, Popp A, Hertwich EG, Luderer $\mathrm{G}$ (2017) Understanding future emissions from low-carbon power systems by integration of life-cycle assessment and integrated energy modelling Nature. Energy 2:939-945. https://doi. org/10.1038/s41560-017-0032-9

Roux C, Schalbart P, Peuportier B (2016) Accounting for temporal variation of electricity production and consumption in the LCA of an energy-efficient house J Clean. Prod 113:532-540. https:// doi.org/10.1016/j.jclepro.2015.11.052

Saltelli A, Annoni P, Azzini I, Campolongo F, Ratto M, Tarantola S (2010) Variance based sensitivity analysis of model output. Design and estimator for the total sensitivity index. Comput 
Phys Commun 181:259-270. https://doi.org/10.1016/j.cpc. 2009.09.018

Sandberg NH, Sartori I, Vestrum MI, Brattebø H (2016) Explaining the historical energy use in dwelling stocks with a segmented dynamic model: Case study of Norway 1960-2015 Energy and Buildings 132:141-153 https://doi.org/10.1016/j.enbuild.2016. 05.099

Saner D, Heeren N, Jäggi B, Waraich RA, Hellweg S (2013) Housing and mobility demands of individual households and their life cycle assessment. Environ Sci Technol 47:5988-5997. https://doi.org/ 10.1021/es304084p

Scott K, Roelich K, Owen A, Barrett J (2018) Extending European energy efficiency standards to include material use: an analysis. Climate Policy 18:627-641. https://doi.org/10.1080/14693062. 2017.1333949

Statistics Norway (2019) Electricity balance (MWh). Norwegian. https://www.ssb.no/en/energi-og-industri/statistikker/elektrisitet. Accessed October 2020

Steinmann ZJN, Schipper AM, Hauck M, Huijbregts MAJ (2016) How Many Environmental Impact Indicators Are Needed in the Evaluation of Product Life Cycles? Environ Sci Technol 50:3913-3919. https://doi.org/10.1021/acs.est.5b05179

Stephan A, Crawford RH (2014) A multi-scale life-cycle energy and greenhouse-gas emissions analysis model for residential buildings. Archit Sci Rev 57:39-48. https://doi.org/10.1080/00038628. 2013.837814

Stephan A, Crawford RH, de Myttenaere K (2013) Multi-scale life cycle energy analysis of a low-density suburban neighbourhood in Melbourne. Australia Building and Environment 68:35-49. https://doi.org/10.1016/j.buildenv.2013.06.003

Stephan A, Stephan L (2016) Life cycle energy and cost analysis of embodied, operational and user-transport energy reduction measures for residential buildings Applied Energy 161:445-464 https:// doi.org/10.1016/j.apenergy.2015.10.023

UNEP (2019) Emissions Gap Report 2019.

UNEP (2020) 2020 Global Status Report for Buildings and Construction: Towards a zero-emissions, efficient and resilient buildings and construction sector.

UNEP, Setac (2016) Global Guidance for Life Cycle Impact Assessment Indicators - Volume 1.
UNEP, SETAC (2019) Global Guidance on Environmental Life Cycle Impact Assessment Indicators - Volume 2.

Vandepaer L, Cloutier J, Bauer C, Amor B (2019a) Integrating Batteries in the Future Swiss Electricity Supply System: A Consequential Environmental Assessment J Ind Ecol 23:709-725. https:// doi.org/10.1111/jiec. 12774

Vandepaer L (2017) Gibon T (2018) The integration of energy scenarios into LCA: LCM2017 Conference Workshop, Luxembourg, September 5. Int J Life Cycle Assess 23:970-977. https://doi.org/ 10.1007/s11367-017-1435-3

Vandepaer L, Treyer K, Mutel C, Bauer C, Amor B (2019b) The integration of long-term marginal electricity supply mixes in the ecoinvent consequential database version 3.4 and examination of modeling choices Int J Life Cycle Assess 24:1409-1428 https:// doi.org/10.1007/s11367-018-1571-4

Wernet G, Bauer C, Steubing B, Reinhard J, Moreno-Ruiz E, Weidema B (2016) The ecoinvent database version 3 (part I): overview and methodology Int J Life Cycle Assess 21:1218-1230 https://doi. org/10.1007/s11367-016-1087-8

Wiebe KS (2018) Identifying emission hotspots for low carbon technology transfers J Clean. Prod 194:243-252. https://doi.org/10. 1016/j.jclepro.2018.05.003

Wiik MK et al. (2018) Zero Emission Neighbourhoods in Smart Cities: Definition, Key Performance Indicators and Assessment Criteria: Version 1.0 vol ZEN report No. 7

Wolfram P, Tu Q, Heeren N, Pauliuk S, Hertwich EG (2020). Material Efficiency and Climate Change Mitigation of Passenger Vehicles J Ind Ecol. https://doi.org/10.1111/jiec.13067

Ydalir (2017) Masterplan - Ydalir, Elverum (part 1) (in Norwegian).

Zhang C, Chen W-Q, Ruth M (2018) Measuring material efficiency: A review of the historical evolution of indicators, methodologies and findings Resour Conserv Recycl 132:79-92 https://doi.org/ 10.1016/j.resconrec.2018.01.028

Zhao X, Zuo J, Wu G, Huang C (2019) A bibliometric review of green building research 2000-2016 Architectural Science Review 62:74-88 https://doi.org/10.1080/00038628.2018.1485548

Publisher's Note Springer Nature remains neutral with regard to jurisdictional claims in published maps and institutional affiliations. 